\title{
Expression of Hepatic Fat-Specific Protein 27 Depends on the Specific Etiology of Fatty Liver
}

\author{
Daisuke Aibara, ${ }^{a}$ Kimihiko Matsusue, ${ }^{*, a}$ Kohei Matsuo, ${ }^{a}$ Soichi Takiguchi, ${ }^{b}$ \\ Frank J. Gonzalez, ${ }^{c}$ and Shigeru Yamano ${ }^{a}$ \\ ${ }^{a}$ Faculty of Pharmaceutical Science, Fukuoka University; 8-19-1 Nanakuma, Jonan-ku, Fukuoka 814-0180, Japan: \\ ${ }^{b}$ Institute for Clinical Research, National Kyushu Cancer Center; 3-1-1 Notame, Minami-ku, Fukuoka 811-1395, \\ Japan: and ${ }^{c}$ Laboratory of Metabolism, National Cancer Institute, National Institutes of Health; Bethesda, Maryland \\ 20892, U.S.A.
}

Received May 8, 2013; accepted August 9, 2013

Fat-specific protein 27 gene (FSP27), isolated by screening for genes specifically expressed in fully differentiated mouse adipocytes, belongs to the cell death-inducing DNA fragmentation factor, alpha subunit-like effector family. FSP27 is induced in not only adipose tissue but also the liver of $o b / o b$ mice, and it promotes the development of fatty liver. The FSP27 gene is expressed in a fatty liver-specific manner and is not detected in the normal mouse liver. FSP27 expression is directly regulated by the induction of the hepatic peroxisome proliferator-activated receptor $\gamma(\operatorname{PPAR} \gamma)$ in $o b / o b$ fatty liver. In the present study, expression of hepatic FSP27 mRNA was determined in non-genetic fatty liver models. The FSP27 gene was markedly induced in the high-fat- or methionine- and choline-deficient (MCD) diet-induced fatty liver, but it was not elevated in alcohol-induced fatty liver. Interestingly, the induction of FSP27 mRNA due to the MCD diet was independent of PPAR $\gamma$ levels and completely absent in the liver from PPAR $\gamma$-null mice. These results suggest that FSP27 mRNA expression in the liver depends on the etiology of fatty liver.

Key words fat-specific protein 27; peroxisome proliferator-activated receptor; fatty liver

Fat-specific protein 27 (FSP27) was originally isolated from fully differentiated mouse adipocytes by screening for specifically expressed genes. ${ }^{1,2)}$ The human homolog of FSP27, i.e., cell death-inducing DNA fragmentation factor, alpha subunitlike effector (CIDE) C, was also isolated from a human liver cDNA library. ${ }^{3)}$ Identification of protein sequence and domain structure classified FSP27 as a member of the CIDE protein family, which also includes CIDEA, CIDEB, and CIDEC/ FSP27. Adipocyte FSP27 was recently reported to be a lipid droplet (LD)-associated protein that promotes the formation of unilocular LDs. ${ }^{4}$ Furthermore, FSP27 knockout mice demonstrated a lean phenotype with atrophic adipose tissue due to high-energy expenditure; this mouse line was also resistant to diet-induced obesity and insulin. ${ }^{5,6}$

In a previous study, we demonstrated that $o b / o b$ mice that are deficient in the nuclear receptor peroxisome proliferator-activated receptor $\gamma(\operatorname{PPAR} \gamma)$, specifically in the liver (ob/ob-PPAR $\gamma \mathrm{KO}$ ), showed dramatic improvement in severe fatty liver disease, suggesting that hepatic $\operatorname{PPAR} \gamma$ promotes the generation of fatty liver. ${ }^{7)}$ To understand the mechanism of PPAR $\gamma$-dependent fatty liver formation, subtractive cDNA cloning was used to compare downstream target genes of hepatic PPAR $\gamma$ in $o b / o b-\mathrm{PPAR} \gamma \mathrm{KO}$ and $o b / o b-\mathrm{PPAR} \gamma$ wildtype mice (ob/ob-PPAR $\gamma \mathrm{WT}$ ); FSP27 cDNA was isolated, and the FSP27 gene was found to be regulated by hepatic PPAR $\gamma$. FSP27 expression markedly decreased in ob/ob-PPAR $\gamma \mathrm{KO}$ liver. Furthermore, forced expression of FSP27 by adenovirus in hepatocytes in vivo and in vitro resulted in an increase of LDs through elevated triglyceride (TG) levels, whereas knockdown of FSP27 in ob/ob mice resulted in the loss of hepatic TG. ${ }^{8)}$ These results strongly suggest that FSP27 is directly associated with hepatic TG accumulation. ${ }^{9 \text { ) }}$

The $o b / o b$ mouse is a well-known genetically leptin-defi-

The authors declare no conflict of interest cient mouse and a typical model for type II diabetes, obesity, and fatty liver. Recently, FSP27 expression was also observed in fatty liver of a new insulin resistant model mouse line, ddY-H. ${ }^{10)}$ Although FSP27 is highly expressed in ob/ob and other mouse models of fatty liver, it remains largely unknown whether other etiologies are involved in the expression of FSP27 in fatty livers. To address this question, the expression of hepatic FSP27 was examined in several fatty liver models, including $d b / d b$ mice, as well as high-fat (HF)-, alcohol (AL)-, and methionine- and choline-deficient (MCD) diet-fed mice. The FSP27 gene was markedly induced in $d b / d b$, and in HFand MCD-induced fatty liver, but not in AL-induced fatty liver. However, hepatic PPAR $\gamma$, a master regulator of FSP27, was induced in $d b / d b$, and in HF and AL fatty livers, but not in MCD fatty liver. Interestingly, the induction of FSP27 in MCD fatty liver was not observed in liver-specific PPAR $\gamma \mathrm{KO}$ mouse liver. Thus, our studies reveal new findings on the regulation of FSP27 in fatty liver and suggest that FSP27 expression in fatty liver is influenced by the etiology of this condition.

\section{MATERIALS AND METHODS}

Animals PPAR $\gamma$ liver-specific knockout mice on an $o b / o b$ or normal genetic background were generated using a floxed PPAR $\gamma$ allele and Cre recombinase under the control of the albumin promoter, as previously described. ${ }^{7)}$ Female diabetic $\mathrm{db} / \mathrm{db}$ mice (C57BL/KsJ-leprdb) and female C57BL/6J wildtype mice were obtained at 8 weeks of age from Nippon CREA (Tokyo, Japan). All animal protocols and studies were performed according to guidelines from the Center for Experimental Animals at Fukuoka University.

MCD and HF Diet Study Female C57BL/6J mice were randomly divided into 2 groups at 8 weeks of age. One group $(n=4)$ of mice was fed a MCD (Oriental Yeast, Japan) or HF 
(A) FSP27

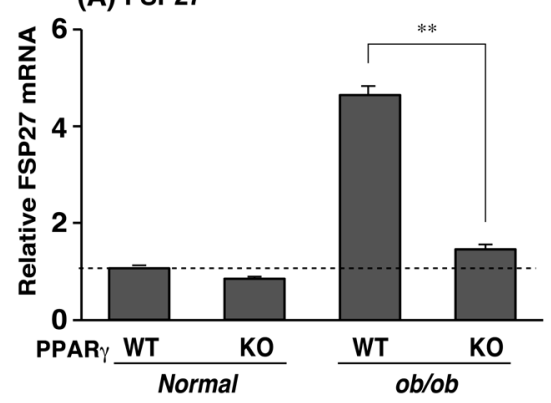

(B) PPAR

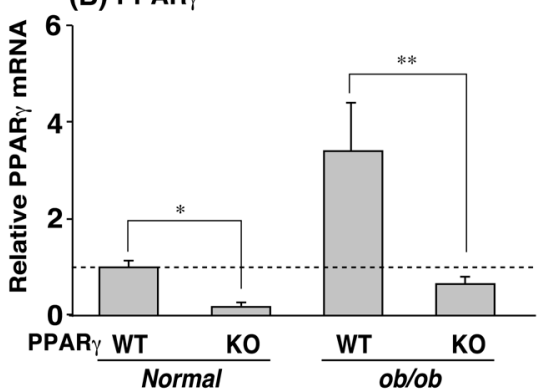

Fig. 1. FSP27 Gene Expression Depends on Hepatic PPAR $\gamma$ Expression

QPCR analyses of FSP27 (A) and PPAR (B) mRNAs were performed in each genotyped mouse liver. Expression was normalized to $36 B 4$ mRNA, and each bar represents the average \pm S.E.M. of three separate experiments. Normal, normal genetic background mice; $o b / o b$, leptin-deficient mice; WT, PPAR $\gamma$ wild-type mice liver; KO, PPAR $\gamma \mathrm{KO}$ mice liver. Note: $o b / o b$-PPAR $\gamma \mathrm{WT}$ mice have fatty liver, whereas $o b / o b$-PPAR $\gamma \mathrm{KO}$ mice are normal or have much less fat. ${ }^{7)}$ Significant differences from PPAR $\gamma$ WT liver: $* p<0.01, * * p<0.001$.

(HFD32; CLEA, Japan) diet ad libitum, while the control group was fed normal chow. Mice were fed with MCD or HF diet for 1 or 2 months, respectively. ${ }^{11,12)}$ Plasma levels of alanine aminotransferase (ALT) and aspartate aminotransferase (AST) were measured using commercial transaminase CII-test Wako kit (Wako Pure Chemical Industries, Ltd.).

Alcohol Diet Study AL diet was administered according to previous studies. ${ }^{13)}$ Female C57BL/6J mice were randomly divided into 2 groups at 8 weeks of age and fed a 4\% ethanolcontaining liquid diet (F2LEW; Oriental Yeast, Japan). For controls, mice were fed the same volume of a control liquid diet (F2LCW; Oriental Yeast), prepared by replacing ethanol with isocaloric sucrose. The mice were fed the AL diet for 2 months.

RNA Extraction and Quantitative Real-Time Polymerase Chain Reaction (PCR) Mouse RNA was extracted using TRIzol reagent (Invitrogen, Carlsbad, CA), and quantitative polymerase chain reaction (QPCR) was performed using complementary DNA (cDNA) generated from $1 \mu \mathrm{g}$ of total RNA with an AffinityScript QPCR cDNA Synthesis kit (Agilent Technologies). Primer sequences used are listed as follows: FSP27: forward, 5'-ATGAAG TCT CTC AGC CTC CTG-3' and reverse, 5'-AAGCTGTGA GCCATGATG C-3'; PPAR : forward, 5'-CAT GGCCAT TGA GTG CCG AGT-3' and reverse, 5'-ACA TCCCCA CAGCAAGGCAC-3'; adipocyte fatty acid-binding protein $(a P 2)$ : forward, 5'-GATGCC TTTGTGGGA ACC TG-3' and reverse, 5'-GAA TTCCAC GCCCAGTTTGA-3'; phosphoenolpyruvate carboxykinase $(P E P C K)$ : forward, 5'-CAT ATGCTGATC CTGGGCATA AC-3' and reverse, 5'-CAA ACT TCA TCC AGGCAA TGT C-3'; fatty acid synthase $(F A S)$ : forward, 5'-GGAGGTGGT GAT AGCCGGTAT-3' and reverse, 5'-TGGGTAATCCAT AGA GCCCAG-3'; sterol regulatory element-binding transcription factorlc (SREBP1c): forward, 5'-GGA GCC ATGGAT TGC ACA TT-3' and reverse, 5'-AGGAAGGCT TCC AGA GAGGA-3'; cluster of differentiation 36 (CD36): forward, 5'-TGGCCT TAC TTGGGA TTGG-3' and reverse, 5'-CCA GTGTATATGTAGGCTCATCCA-3'; and acidic ribosomal phosphoprotein P0 (36B4): forward, 5'-AAACTGCTGCCT CACATCCG-3' and reverse, 5'-TGG TGCCTC TGG AGA TTTTCG-3' QPCR reactions were carried out using Brilliant III Ultra-Fast SYBR Green QPCR Master Mix (Agilent Technologies) in an Mx3005P Real-Time PCR System (Agilent Technologies). Values of sample mRNAs were normalized to

\section{$36 B 4$ mRNA.}

Hepatic TG Measurement To measure liver TG concentrations, total lipids were extracted using the following protocol. Hepatic TG was extracted from $0.1 \mathrm{~g}$ of liver and homogenized in $1 \mathrm{~mL}$ of $0.1 \mathrm{M} \mathrm{KCl}$. In a new tube, $50 \mu \mathrm{L}$ of homogenates was diluted by adding $50 \mu \mathrm{L}$ of $0.1 \mathrm{M} \mathrm{KCl}$, followed by $0.375 \mathrm{~mL}$ of chloroform-methanol $(1: 2)$. Following vortexing, the mixture was kept at room temperature for $5 \mathrm{~min}$, after which $0.125 \mathrm{~mL}$ of chloroform was added to the tube and vortexed. Next, $0.125 \mathrm{~mL}$ of water was added followed by vortexing again. After centrifugation at $16000 \times \boldsymbol{g}$ for $15 \mathrm{~min}$, the organic layer was transferred to another tube. For complete extraction of liver lipid, an additional extraction was repeated using $100 \mu \mathrm{L}$ of chloroform. Lipids dissolved in organic solvents were dried down and re-suspended in the enzymatic kit buffers prior to TG assays performed using commercial kits (Sekisui Medical).

Statistical Analysis Experimental values are expressed as mean \pm standard error of the mean (SEM). Statistical analysis was performed by Student's $t$-test for unpaired data, with $p<0.05$ considered statistically significant.

\section{RESULTS}

FSP27 Expression in the ob/ob Mouse Is Induced by PPAR $\gamma$ and Depends on Fatty Liver Formation To evaluate and quantify the levels of FSP27 gene expression in $o b / o b$-PPAR $\gamma \mathrm{KO}$ and $o b / o b-\mathrm{PPAR} \gamma \mathrm{WT}$ livers, QPCR was carried out on cDNAs from each genotype. Expression of FSP27 mRNA observed in $o b / o b$-PPAR $\gamma$ WT liver was 5-fold higher than normal mouse PPAR $\gamma \mathrm{WT}$ or KO livers. Expression of FSP27 mRNA in ob/ob-PPAR $\gamma \mathrm{KO}$ liver was only $25 \%$ of levels in $o b / o b$-PPAR $\gamma \mathrm{WT}$ liver (Fig. 1A). While hepatic $P P A R \gamma$ mRNA in $o b / o b$-PPAR $\gamma$ WT liver was approximately 3.5-fold higher than normal mouse PPAR $\gamma \mathrm{WT}$ liver (Fig. 1B). FSP27 expression was markedly lower in $o b / o b$-PPAR $\gamma \mathrm{KO}$ liver relative to normal mouse PPAR $\gamma \mathrm{WT}$ liver. To evaluate the potency of PPAR $\gamma$ as an FSP27 inducer, PPAR $\gamma$ was overexpressed in liver-derived AML-12 cells by using a PPAR $\gamma$-adenoviral vector; AML-12 cells do not constitutively express $P P A R \gamma$ or FSP27. Expression of FSP27 mRNA in AML-12 cells was induced approximately 7-fold and 200-fold without and with the PPAR $\gamma$-specific ligand, rosiglitazone, respectively, compared with control adenoviral vector (data not shown). These 
results suggest that FSP27 is a fatty liver-specific gene and that PPAR $\gamma$ expression in the liver is a critical trigger for the ectopic induction of FSP27 mRNA.

FSP27 mRNA Is Induced in $d b / d b$, HF, and MCD Fatty Livers, but Not in AL Fatty Liver The expression of FSP27 mRNA was low in normal liver, but high in $o b / o b$ fatty liver, raising the question of whether FSP27 is also expressed in the fatty livers as a result of different etiologies. To address this question, we used different fatty liver mouse models, namely, HF-, AL-, and MCD diet-fed and leptin receptormutated $d b / d b$ mice. Biochemical parameters for each fatty liver model are summarized in Table 1. TG levels in all livers examined were $>2$-fold higher than that in the control groups.

The $d b / d b, \mathrm{HF}$, and MCD fatty livers showed a 12-, 5-, and 7-fold increase, respectively, in FSP27 mRNA compared to control groups (Figs. 2A, B, D). However, no significant differences in FSP27 mRNA were observed between control and AL groups (Fig. 2C). To elucidate the induction mechanism of $F S P 27$ in the fatty livers, $P P A R \gamma$ expression was also evaluated in these samples. The $d b / d b$ and HF fatty livers displayed approximately a 1.6- and 1.8-fold increase in PPAR $\gamma$ mRNA, which positively correlated with FSP27 mRNA expression (Figs. 2A, B). AL fatty liver showed approximately a 2.8 -fold increase in PPAR $\mathrm{mRNA}$, whereas FSP27 mRNA remained unchanged (Fig. 2C). Conversely, no significant differences in $P P A R \gamma$ mRNA were observed between the control and MCD groups (Fig. 2D); nevertheless, FSP27 mRNA was markedly induced by this diet. Furthermore, $a P 2$ and $C D 36$ mRNAs, which are known as typical targets of PPAR $\gamma$ significantly increased in the $d b / d b, \mathrm{HF}$, and AL fatty livers. Interestingly, the expression of these genes in MCD fatty liver was unchanged. These findings results suggest that FSP27 gene expression is not always dependent on increases in PPAR $\gamma$ expression, and potentially represent a distinct etiology of fatty liver.

Hepatic PPARy in MCD Fatty Liver Regulates FSP27 Expression The MCD diet is frequently used for the generation of fatty liver and nonalcoholic steatohepatitis. ${ }^{14)}$ Unlike the $o b / o b, d b / d b$, and HF fatty liver mouse models, mice fed a MCD diet showed a tendency toward low hepatic PPAR $\gamma$ and high FSP27 mRNA levels relative to control mice (Fig. 2D). Thus, to evaluate the potential of hepatic PPAR $\gamma$ as an inducer of FSP27 mRNA in MCD fatty liver, PPAR $\gamma \mathrm{KO}$ mice from a normal genetic background were administered a MCD diet. This treatment markedly induced the expression of FSP27 mRNA in PPAR $\gamma \mathrm{WT}$ mice, but not in PPAR $\gamma \mathrm{KO}$ mice, which displayed expression levels similar to those in mice fed the control diet (Figs. 3A, B). These results suggest that PPAR $\gamma$ in MCD fatty liver is functional and regulates FSP27 mRNA expression.

FSP27 Induced in MCD Fatty Liver Is Not Associated with Hepatic TG Levels Previous reports demonstrated that FSP27 induced in $o b / o b$ fatty liver promotes the development of fatty liver by stimulating the accumulation of hepatic TG. ${ }^{8)}$ To examine the association between FSP27 and hepatic TG content, TG levels were measured in the livers of PPAR $\gamma \mathrm{KO}$ mice that had been fed a MCD diet. No significant differences in hepatic TG content were observed between PPAR $\gamma \mathrm{WT}$ and KO mice that were fed a MCD diet (Fig. 4A).

The expression of genes involved in de novo lipogenesis, such as FAS and SREBPIc, or those involved glucose metabolism, such as $P E P C K$, remained largely unchanged in PPAR $\gamma \mathrm{WT}$ and KO mice fed a MCD diet (Fig. 4B). Interestingly, mRNA of the $a P 2$ gene also remained unchanged in these mice (Fig. 4B). The MCD diet promotes steatohepatitis and fibrosis in mice; hence, mRNAs levels of the fibrosis marker genes alpha-smooth-muscle actin, tissue inhibitor of metalloproteinase 1, and collagen type I were measured. However, these mRNAs remained unchanged in PPAR $\gamma \mathrm{WT}$ and PPAR $\gamma \mathrm{KO}$ mice that had been fed the MCD diet (data not shown).

\section{DISCUSSION}

PPAR $\gamma$ expression was the highest in adipose tissue, ${ }^{15,16)}$ and was present at measurable levels in the colon epithelium ${ }^{17,18)}$ and macrophages. ${ }^{19)}$ PPAR $\gamma$ is induced in $o b / o b$ mouse liver, and it is critical for the development of fatty liver. ${ }^{7)}$ Elevated PPAR $\gamma$ levels in ob/ob fatty liver induces FSP27 expression; the induced FSP27 then coordinates with factors in the lipogenic pathway to elevate hepatic triglyceride levels. ${ }^{8)}$ From these earlier studies, we concluded that activation of the PPAR $\gamma$-FSP27 signal that leads to TG accumulation in the liver is triggered by elevated PPAR $\gamma$ expression in the liver, although the molecular mechanism responsible for elevated hepatic PPAR $\gamma$ expression levels remains unclear. In the present study, we demonstrated that the expression of hepatic FSP27 depends on the etiology of fatty liver. Indeed, FSP27 expression remained unchanged in AL fatty liver, despite elevated $P P A R \gamma$ mRNA. Contrary to the observations in AL fatty liver, it is noteworthy that FSP27 was highly expressed in MCD fatty liver without the elevation of $P P A R \gamma$ mRNA. In addition, the results from liver-specific PPAR $\gamma$-null mice revealed that FSP27 induced in MCD fatty liver is regulated by constitutively expressed hepatic PPAR $\gamma^{20)}$

Table 1. Biochemical Parameters of Each Fatty Liver Model Mouse

\begin{tabular}{|c|c|c|c|c|c|c|c|c|}
\hline Parameters & $d b / m$ & $d b / d b$ & Cont (HF) & $\mathrm{HF}$ & Cont (AL) & $\mathrm{AL}$ & Cont (MCD) & MCD \\
\hline $\begin{array}{l}\text { Body weight } \\
\text { (g) }\end{array}$ & $23 \pm 0.1$ & $55 \pm 0.8 * * *$ & $22 \pm 0.3$ & $38 \pm 3.3 *$ & $30 \pm 0.3$ & $24 \pm 1.5^{*}$ & $21 \pm 0.7$ & $13 \pm 0.0 * * *$ \\
\hline $\begin{array}{l}\text { Liver weight } \\
\text { (g) }\end{array}$ & $1.1 \pm 0.0$ & $2.7 \pm 0.1^{* *}$ & $0.98 \pm 0.0$ & $1.4 \pm 0.2$ & $1.1 \pm 0.0$ & $1.2 \pm 0.1$ & $0.87 \pm 0.0$ & $0.38 \pm 0.0 * * *$ \\
\hline $\begin{array}{l}\text { Liver TG } \\
\quad(\mathrm{mg} / \mathrm{g} \text { liver })\end{array}$ & $2.4 \pm 0.1$ & $6.0 \pm 0.9^{*}$ & $6.6 \pm 0.7$ & $14 \pm 2.0 *$ & $11 \pm 1.0$ & $22 \pm 5.1 *$ & $4.0 \pm 0.2$ & $11 \pm 2.1^{*}$ \\
\hline AST (IU/L) & $114 \pm 8.0$ & $146 \pm 25$ & N.D. & N.D. & N.D. & N.D. & $25 \pm 0.59$ & $43 \pm 5.5^{*}$ \\
\hline ALT (IU/L) & $30 \pm 8.7$ & $49 \pm 2.7$ & N.D. & N.D. & N.D. & N.D. & $2.9 \pm 0.34$ & $7.4 \pm 4.3 * *$ \\
\hline
\end{tabular}

Each group contains 3-4 mice. Cont, untreated control mice; TG, triglyceride; AST, aspartate aminotransferase activity; ALT, alanine aminotransferase activity. N.D., no determined. Values are mean \pm S.E.M. Significant differences from $d b / m$ mice or control diet: $* p<0.05, * * p<0.01, * * * p<0.001$. 
(A) $d b / d b$

FSP27

PPAR $\gamma$

aP2

CD36
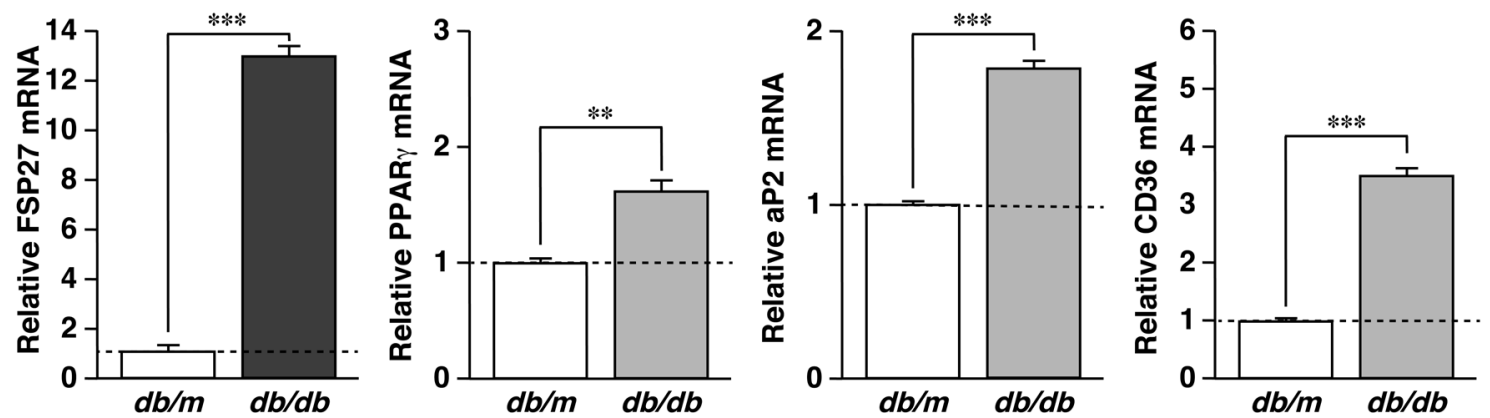

(B) HF
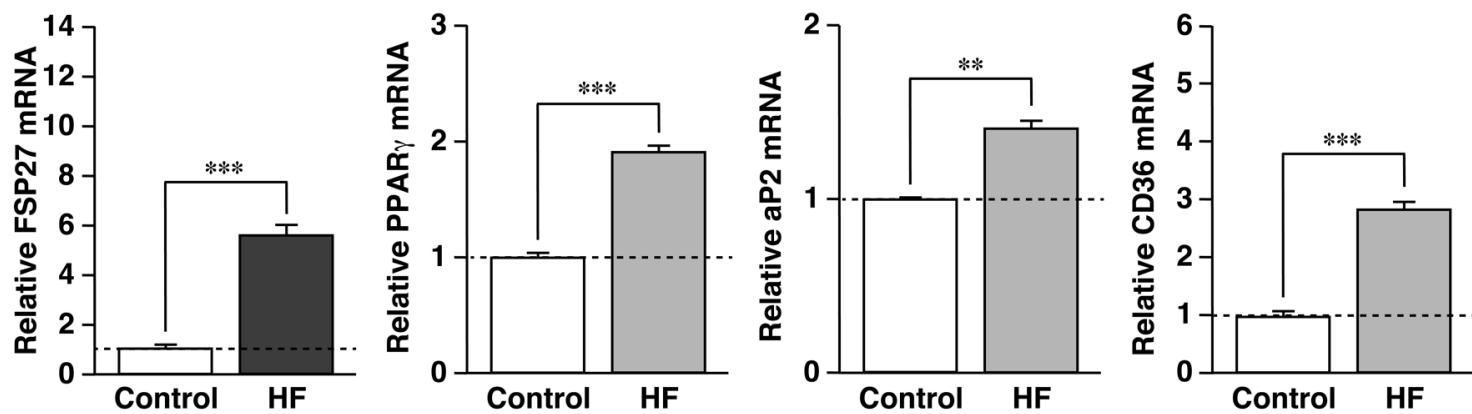

(C) $\mathrm{AL}$
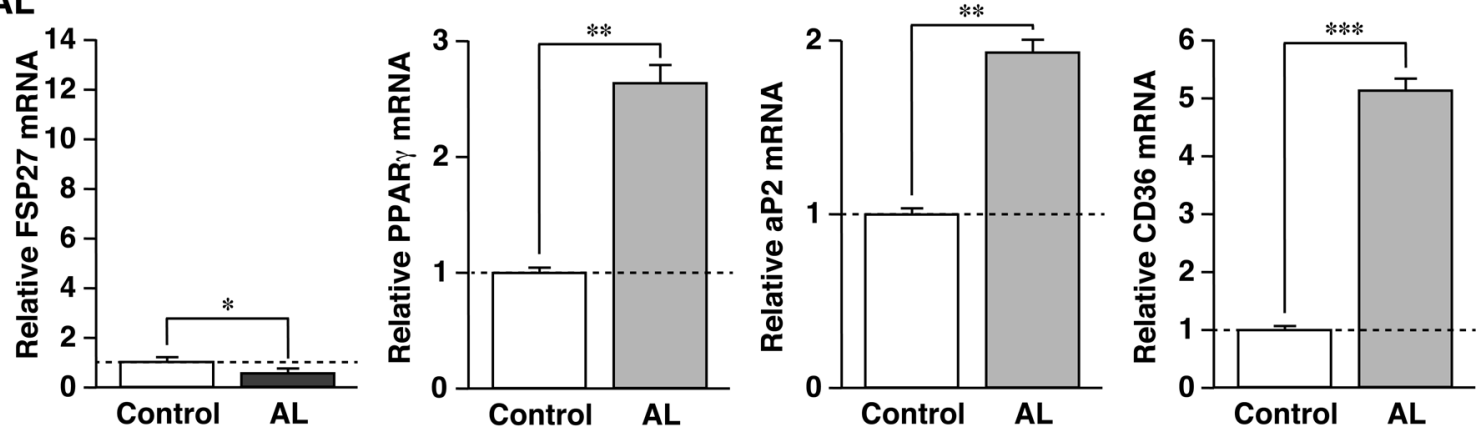

(D) MCD
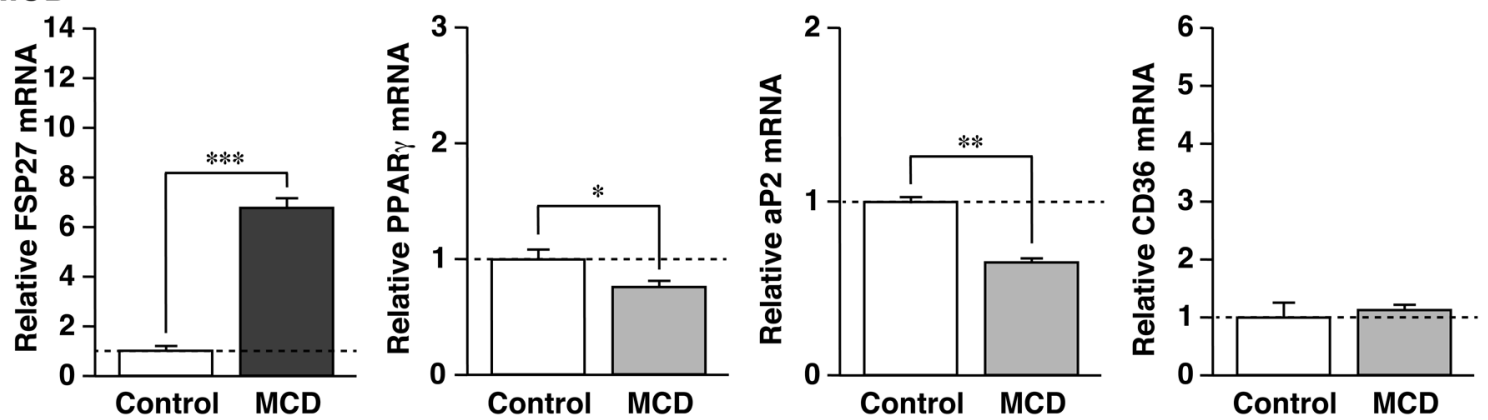

Fig. 2. FSP27 Gene Expression in Fatty Livers Developed by Different Methods

QPCR analyses of FSP27, PPAR , aP2, and CD36 mRNAs were performed using liver samples from each group. Expression of each mRNA was examined in genetically modified (A) leptin receptor-mutated mice $(d b / d b)$, as well as in mice fed diets comprising either (B) high fat (HF), (C) alcohol (AL), or (D) lacking methionine and choline (MCD). Expression was normalized to $36 B 4 \mathrm{mRNA}$, and each bar represents the average \pm S.E.M. of 3 individual experiments. Significant differences from $d b / m$ mice or control diet: $* p<0.05, * * p<0.01, * * * p<0.001$

Because all commercial FSP27 antibodies obtained from the 4 companies were not available for the Western blot analysis, a customized FSP27 antibody was newly prepared from the synthesized FSP27 peptides. Unfortunately, we could not estimate the native FSP27 protein level in MCD fatty liver because the antibody was not specific. However, we believe that the MCD diet induces not only FSP27 mRNA level but also FSP27 protein level as compared with the control diet.
$P P A R \gamma$ and other PPAR $\gamma$-targets, $a P 2$ and CD36 mRNAs, showed an increase in AL fatty liver, but FSP27 mRNA was unchanged. While, no significant differences in $P P A R \gamma, a P 2$, and CD36 mRNAs were observed between the control and MCD groups, FSP27 mRNA was markedly induced by this diet. The reason for the discrepancy between AL and MCD fatty liver expression of FSP27 are not currently understood. However, our results suggest that the transcriptional regulation 

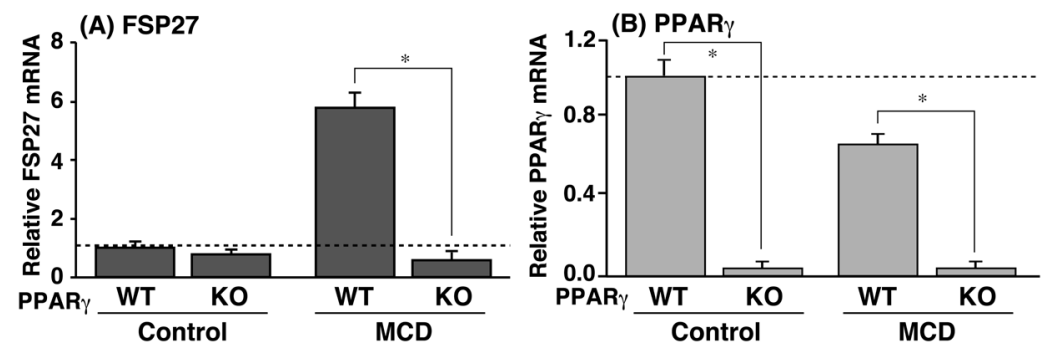

Fig. 3. Induction of FSP27 mRNA in MCD Fatty Liver Is Potentially Regulated by Hepatic PPAR $\gamma$

QPCR analysis of FSP27 (A) and PPAR (B) mRNAs were performed using liver samples from each genotyped mouse. Expression was normalized to $36 B 4$ mRNA, and each bar represents the average \pm S.E.M. of 3 individual experiments. Significant differences from PPAR $\gamma \mathrm{WT}$ liver: ${ }^{*} p<0.001$

(A)

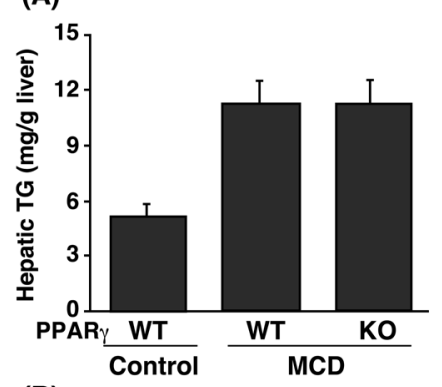

(B)
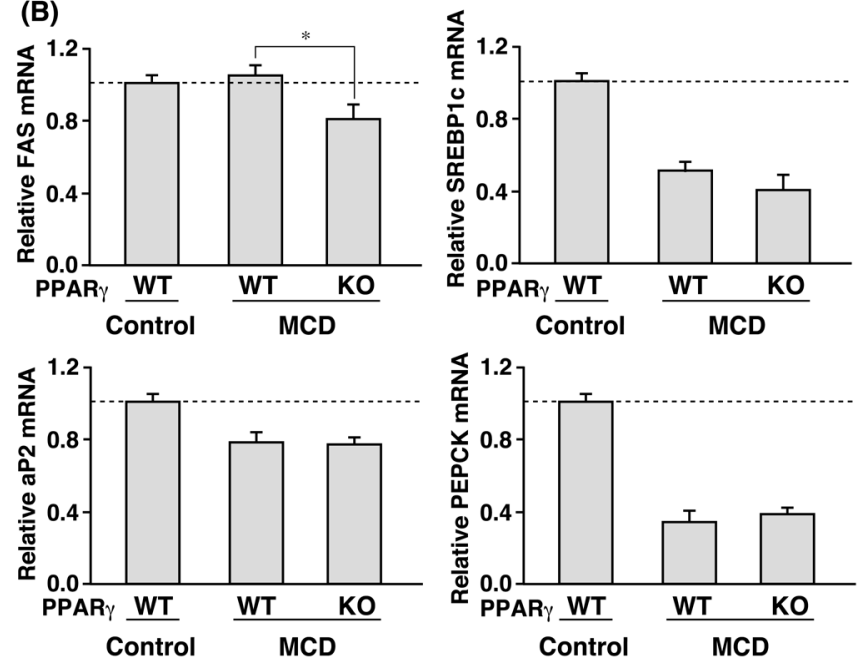

Fig. 4. Hepatic TG Content in MCD Fatty Liver Is Independent of FSP27 Levels

(A) Hepatic TG content in PPAR $\gamma \mathrm{WT}$ and PPAR $\gamma \mathrm{KO}$ mice fed a MCD diet. Each bar represents the average \pm S.E.M. of 3 individual experiments. (B) QPCR analysis to assess the effects of PPAR $\gamma$ deficiency on hepatic gene expression. QPCR analyses of FAS, SREBPIc, aP2, and PEPCK mRNAs were performed using liver samples for each genotyped mouse. Expression was normalized to $36 B 4$ mRNA, and each bar represents the average \pm S.E.M. of 3 individual experiments. Note: no significant differences on all data were observed between PPAR $\gamma \mathrm{WT}$ and PPAR $\gamma$ KO mice fed a MCD diet.

of FSP27 by PPAR $\gamma$ differs from that of other PPAR $\gamma$ targets such as $a P 2$ and $C D 36$. We assume that the regulation of hepatic FSP27 requires PPAR $\gamma$ as well as an unknown factor other than PPAR $\gamma$, and this unknown factor may be repressed in AL fatty liver. It is possible, therefore, that FSP27 mRNA in AL fatty liver remains unchanged even when $a P 2$ and CD36 mRNA levels are elevated. Additionally, this factor is likely to potentially accelerate the function of hepatic PPAR $\gamma$ because FSP27 mRNA levels in MCD fatty liver increased without any increase in $P P A R \gamma$ mRNA levels. Recently, it has been reported that hepatic FSP27 is directly regulated by
cAMP response element-binding protein (CREB), independent of regulation by PPAR $\gamma{ }^{21)}$ It remains unclear whether CREB associates with FSP27 expression in AL fatty liver. We propose that the regulation of FSP27 may be more complicated with the participation of multiple factors.

Recently, a novel regulatory mechanism of hepatic FSP27 through mitogen-activated protein kinase (MAPK) phosphatase-1 (MKP-1) was reported. The study showed that FSP27 mRNA was repressed in fatty livers of both $d b / d b$ and HF-fed mice lacking MKP-1.22) The function of PPAR $\gamma$ is controlled by multiple factors, including ligand binding and phosphorylation by the MAPKs. Specifically, extracellular signal-regulated kinase (ERK) 1/2 and c-Jun N-terminal kinase (JNK) phosphorylate PPAR $\gamma 1$ and PPAR $\gamma 2$ on Ser84 and Ser112, respectively, resulting in decreased PPAR $\gamma$ ligand binding and transcriptional activity. ${ }^{23,24)}$ Thus, dephosphorylation by MKP-1 restores PPAR $\gamma$ function by decreasing MAPK-dependent phosphorylation of PPAR $\gamma$, leading to increased FSP27 mRNA levels. However, the mechanism for MKP-1-mediated upregulation of FSP27 is not likely to be involved in the increase in FSP27 mRNA levels in MCD fatty liver observed in this study, because the MCD diet generally induces an increase in the levels of MAPK activity that promotes phosphorylation by JNK and ERK. ${ }^{25,26)}$

The physiological function of FSP27 in MCD fatty liver remains unclear. We demonstrated that FSP27 expression in the $o b / o b$ fatty liver leads to increased in vitro or in vivo triglyceride levels and that FSP27 is a direct mediator of PPAR $\gamma$ dependent fatty liver generation. ${ }^{8)}$ However, the present study shows that hepatic TG levels in PPAR $\gamma \mathrm{WT}$ mice relative to the PPAR $\gamma \mathrm{KO}$ mice, both of which received the MCD diet, remained unchanged, whereas FSP27 in PPAR $\gamma \mathrm{KO}$ mouse liver dramatically decreased compared to that in $\mathrm{PPAR} \gamma \mathrm{WT}$ mouse liver. Unlike the situation in $o b / o b$ fatty liver, this discrepancy may be due to a large influence of unknown TG accumulation pathways, with the exception of the PPAR $\gamma$-FSP27 signaling pathway activity in MCD fatty liver. For example, it is generally known that methionine and choline deficiencies result in the accumulation of TG because of the decrease of very low-density lipoprotein (VLDL) synthesis. ${ }^{14)}$ This mechanism greatly contributes toward TG accumulation, and the decrease of FSP27 in MCD fatty liver may therefore be a negligible influence. While a function of FSP27 other than TG accumulation induced in MCD fatty liver cannot be ruled out, it has been reported that FSP27 induces apoptosis via caspase-3, caspase-7, and caspase-9, and triggers the release of cytochrome $c$ from the mitochondria, which implies that the mitochondrial pathway is involved in FSP27-induced apo- 
ptosis. $^{27-29)}$ Indeed, the consumption of a MCD diet induced caspase- 3 activity and apoptosis in liver. ${ }^{30)}$ More studies are needed to elucidate the function of FSP27 in MCD fatty liver.

Recent studies have demonstrated CIDEC (human homolog of mouse FSP27) gene expression in the livers of obese human subjects before and after undergoing gastric bypass surgery. ${ }^{31)}$ This procedure reduced obesity through loss of body weight. One year after surgery, the hepatic steatosis grade of subjects significantly decreased relative to pre-surgery conditions, and CIDEC expression in the liver showed a decline of $>60 \%$. Further, PPAR $\gamma$ expression was significantly decreased in the post-surgery liver. These data suggest a positive correlation between human $C I D E C$ expression and hepatic steatosis grade. Elucidation of the physiological function of the CIDEC/ FSP27 pathway potentially may lead to new therapeutic opportunities for inhibiting TG accumulation in the liver.

Acknowledgments This work was supported by a Grant from the Mochida Memorial Foundation for Medical and from KAKENHI (22590253).

\section{REFERENCES}

1) Danesch U, Hoeck W, Ringold GM. Cloning and transcriptional regulation of a novel adipocyte-specific gene, FSP27. CAATenhancer-binding protein $(\mathrm{C} / \mathrm{EBP})$ and $\mathrm{C} / \mathrm{EBP}-$ like proteins interact with sequences required for differentiation-dependent expression. $J$. Biol. Chem., 267, 7185-7193 (1992).

2) Williams PM, Chang DJ, Danesch U, Ringold GM, Heller RA. CCAAT/enhancer binding protein expression is rapidly extinguished in TA1 adipocyte cells treated with tumor necrosis factor. Mol. Endocrinol., 6, 1135-1141 (1992).

3) Liang L, Zhao M, Xu Z, Yokoyama KK, Li T. Molecular cloning and characterization of CIDE-3, a novel member of the cell-deathinducing DNA-fragmentation-factor (DFF45)-like effector family. Biochem. J., 370, 195-203 (2003).

4) Puri V, Konda S, Ranjit S, Aouadi M, Chawla A, Chouinard M, Chakladar A, Czech MP. Fat-specific protein 27, a novel lipid droplet protein that enhances triglyceride storage. J. Biol. Chem., 282, 34213-34218 (2007).

5) Nishino N, Tamori Y, Tateya S, Kawaguchi T, Shibakusa T, Mizunoya W, Inoue K, Kitazawa R, Kitazawa S, Matsuki Y, Hiramatsu R, Masubuchi S, Omachi A, Kimura K, Saito M, Amo T, Ohta S, Yamaguchi T, Osumi T, Cheng J, Fujimoto T, Nakao H, Nakao K, Aiba A, Okamura H, Fushiki T, Kasuga M. FSP27 contributes to efficient energy storage in murine white adipocytes by promoting the formation of unilocular lipid droplets. J. Clin. Invest., 118, 2808-2821 (2008).

6) Toh SY, Gong J, Du G, Li JZ, Yang S, Ye J, Yao H, Zhang Y, Xue B, Li Q, Yang H, Wen Z, Li P. Up-regulation of mitochondrial activity and acquirement of brown adipose tissue-like property in the white adipose tissue of fsp27 deficient mice. PLoS ONE, 3, e2890 (2008).

7) Matsusue K, Haluzik M, Lambert G, Yim SH, Gavrilova O, Ward JM, Brewer B Jr, Reitman ML, Gonzalez FJ. Liver-specific disruption of PPARgamma in leptin-deficient mice improves fatty liver but aggravates diabetic phenotypes. J. Clin. Invest., 111, 737-747 (2003).

8) Matsusue K, Kusakabe T, Noguchi T, Takiguchi S, Suzuki T, Yamano S, Gonzalez FJ. Hepatic steatosis in leptin-deficient mice is promoted by the PPARgamma target gene Fsp27. Cell Metab., 7, 302-311 (2008).

9) Okumura T. Role of lipid droplet proteins in liver steatosis. $J$. Physiol. Biochem., 67, 629-636 (2011).
10) Satoh H, Ide N, Kagawa Y, Maeda T. Hepatic steatosis with relation to increased expression of peroxisome proliferator-activated receptor- $\gamma$ in insulin resistant mice. Biol. Pharm. Bull., 36, 616-623 (2013).

11) Sugimoto H, Okada K, Shoda J, Warabi E, Ishige K, Ueda T, Taguchi K, Yanagawa T, Nakahara A, Hyodo I, Ishii T, Yamamoto M. Deletion of nuclear factor-E2-related factor-2 leads to rapid onset and progression of nutritional steatohepatitis in mice. Am. J. Physiol. Gastrointest. Liver Physiol., 298, G283-G294 (2010).

12) Yokota $T$, Kinugawa $S$, Hirabayashi $K$, Matsushima $S$, Inoue $N$, Ohta Y, Hamaguchi S, Sobirin MA, Ono T, Suga T, Kuroda S, Tanaka S, Terasaki F, Okita K, Tsutsui H. Oxidative stress in skeletal muscle impairs mitochondrial respiration and limits exercise capacity in type 2 diabetic mice. Am. J. Physiol. Heart Circ. Physiol., 297, H1069-H1077 (2009).

13) Nakajima T, Kamijo Y, Tanaka N, Sugiyama E, Tanaka E, Kiyosawa K, Fukushima Y, Peters JM, Gonzalez FJ, Aoyama T. Peroxisome proliferator-activated receptor alpha protects against alcoholinduced liver damage. Hepatology, 40, 972-980 (2004).

14) Hebbard L, George J. Animal models of nonalcoholic fatty liver disease. Nat. Rev. Gastroenterol. Hepatol., 8, 35-44 (2011).

15) Chawla A, Schwarz EJ, Dimaculangan DD, Lazar MA. Peroxisome proliferator-activated receptor (PPAR) gamma. adipose-predominant expression and induction early in adipocyte differentiation. Endocrinology, 135, 798-800 (1994).

16) Tontonoz P, Hu E, Graves RA, Budavari AI, Spiegelman BM. mPPAR gamma 2: tissue-specific regulator of an adipocyte enhancer. Genes Dev., 8, 1224-1234 (1994).

17) Lefebvre AM, Chen I, Desreumaux P, Najib J, Fruchart JC, Geboes K, Briggs M, Heyman R, Auwerx J. Activation of the peroxisome proliferator-activated receptor gamma promotes the development of colon tumors in C57BL/6J-APCMin/+ mice. Nat. Med., 4, 10531057 (1998).

18) Saez E, Tontonoz P, Nelson MC, Alvarez JG, Ming UT, Baird SM, Thomazy VA, Evans RM. Activators of the nuclear receptor PPARgamma enhance colon polyp formation. Nat. Med., 4, 1058-1061 (1998).

19) Moore KJ, Fitzgerald ML, Freeman MW. Peroxisome proliferatoractivated receptors in macrophage biology: friend or foe? Curr. Opin. Lipidol., 12, 519-527 (2001).

20) Kliewer SA, Lenhard JM, Willson TM, Patel I, Morris DC, Lehmann JM. A prostaglandin J2 metabolite binds peroxisome proliferator-activated receptor gamma and promotes adipocyte differentiation. Cell, 83, 813-819 (1995).

21) Vila-Brau A, De Sousa-Coelho AL, Goncalves JF, Haro D, Marrero PF. Fsp27/CIDEC is a CREB target gene induced during early fasting in liver and regulated by FA oxidation rate. J. Lipid Res., 54, 592-601 (2013).

22) Roth Flach RJ, Zhang L, Qin H, Bennett A. Loss of MAP kinase phosphatase-1 protects from hepatic steatosis by repression of CIDEC/fat-specific protein 27. J. Biol. Chem., 286, 22195-22202 (2011).

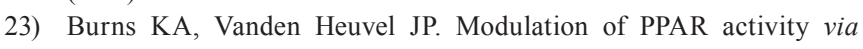
phosphorylation. Biochim. Biophys. Acta, 1771, 952-960 (2007).

24) $\mathrm{Hu}$ E, Kim JB, Sarraf P, Spiegelman BM. Inhibition of adipogenesis through MAP kinase-mediated phosphorylation of PPARgamma. Science, 274, 2100-2103 (1996).

25) Schattenberg JM, Singh R, Wang Y, Lefkowitch JH, Rigoli RM, Scherer PE, Czaja MJ. JNK1 but not JNK2 promotes the development of steatohepatitis in mice. Hepatology, 43, 163-172 (2006).

26) Min AK, Kim MK, Kim HS, Seo HY, Lee KU, Kim JG, Park KG, Lee IK. Alpha-lipoic acid attenuates methionine choline deficient diet-induced steatohepatitis in C57BL/6 mice. Life Sci., 90, 200-205 (2012).

27) Yonezawa $T$, Kurata R, Kimura M, Inoko H. Which CIDE are you on? Apoptosis and energy metabolism. Mol. Biosyst., 7, 91-100 
(2011).

28) Liu K, Zhou S, Kim J-Y, Tillison K, Majors D, Rearick D, Lee JH, Fernandez-Boyanapalli RF, Barricklow K, Houston MS, Smas CM. Functional analysis of FSP27 protein regions for lipid droplet localization, caspase-dependent apoptosis, and dimerization with CIDEA. Am. J. Physiol. Endocrinol. Metab., 297, E1395-E1413 (2009).

29) Kim J-Y, Liu K, Zhou S, Tillison K, Wu Y, Smas CM. Assessment of fat-specific protein 27 in the adipocyte lineage suggests a dual role for FSP27 in adipocyte metabolism and cell death. Am. $J$. Physiol. Endocrinol. Metab., 294, E654-E667 (2008).

30) Dixon LJ, Berk M, Thapaliya S, Papouchado BG, Feldstein AE. Caspase-1-mediated regulation of fibrogenesis in diet-induced steatohepatitis. Lab. Invest., 92, 713-723 (2012).

31) Hall AM, Brunt EM, Klein S, Finck BN. Hepatic expression of cell death-inducing dffa-like effector $\mathrm{C}$ in obese subjects is reduced by marked weight loss. Obesity (Silver Spring), 18, 417-419 (2010). 